التحليل الكينماتيكي للضرية المستقيمة الخلفية كأساس لتطوير بعض

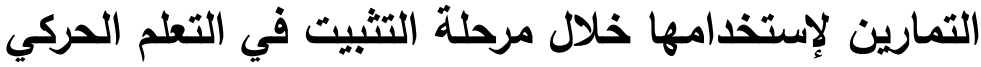
برياضة الاسكواش لماشن

"د/ هشام محمد عبد الحليم عبد الكريم

المقدمة ومشكلة البحث :

الإسكواش هو أحد رياضات المضرب حيث يعتمد على الهجوم والدفاع

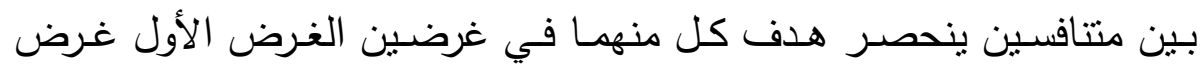
هجومي في إحراز النقاط المكونة لأشواط المباراة والغرض الثاني غرض غناض دفاعي

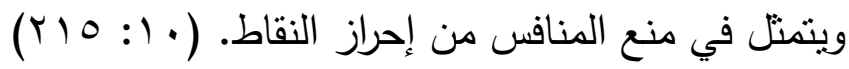

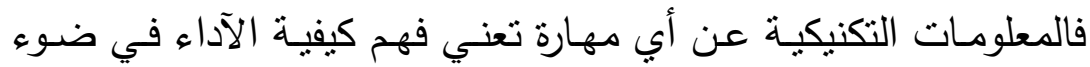
مجموعة من المعلومات التي تساعد على تحديد الإجراءات الحركية المطلوبـة

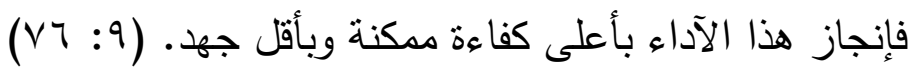

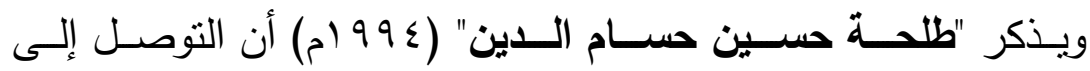

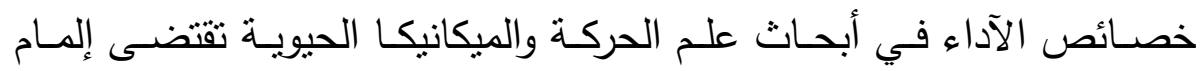

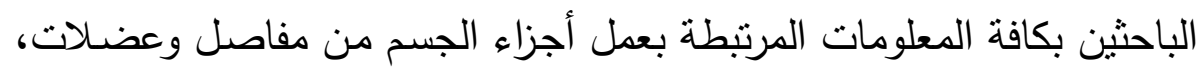

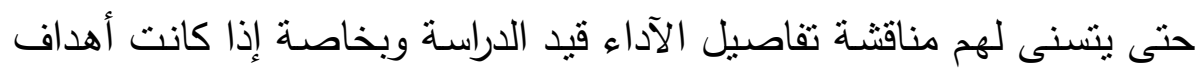

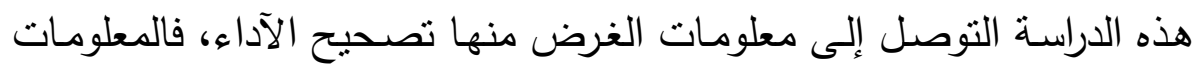

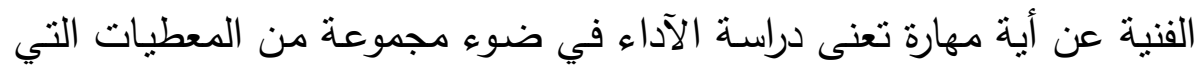

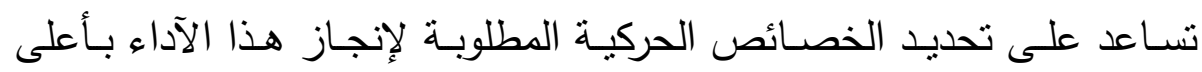

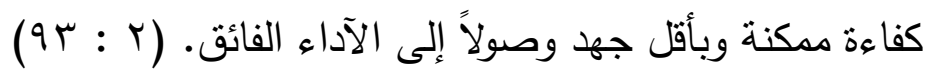

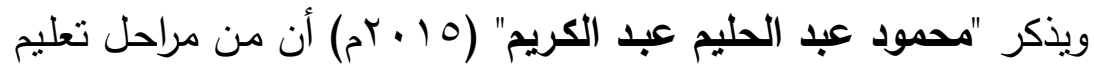

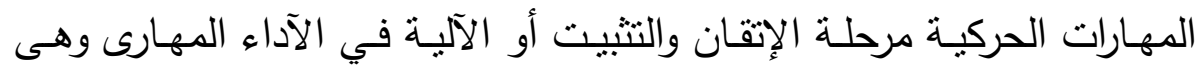

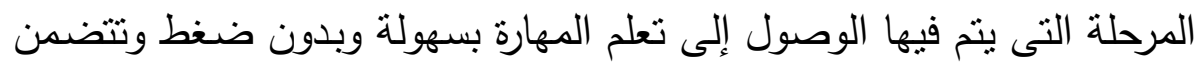

" مدرس منتدب بقسم المناهج وتدريس التربية الرياضية (تخصص ألعاب مضـرب) كلية مجلة أسيوط لعلوم وفنون التربية الرياضية التربية الرباضية- جامعة أسيوط. 
عمليات تغيير القوة والسرعة والجهد والثكل حتى يتمكن المتعلم من التكيف مـع

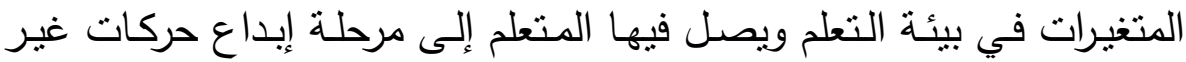

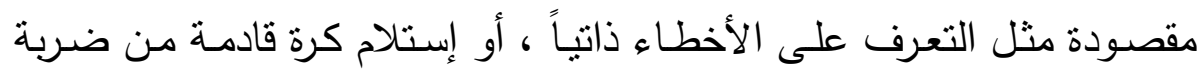

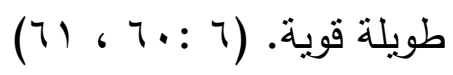

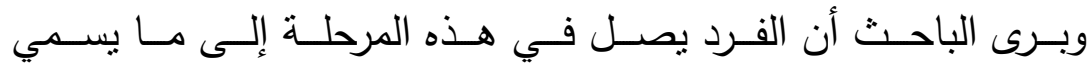

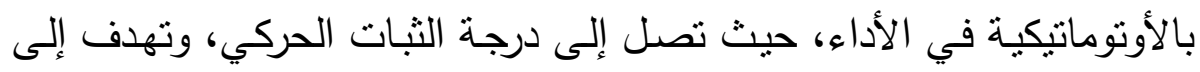
الوصـول بالحركة إلى أقصىى وأدق توافق حركي ممكن حتى تثبت وتشـتقر

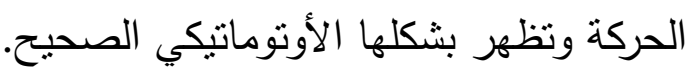

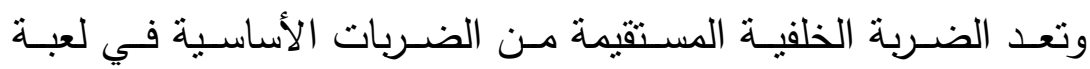
الإسكواش وتؤدى هذه الضربة من الضرب بالجهة المعاكسـة للذراع الضـاربة

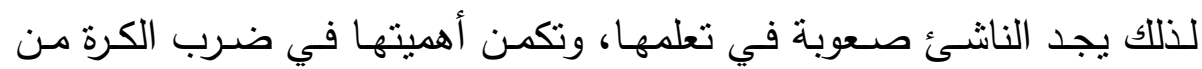

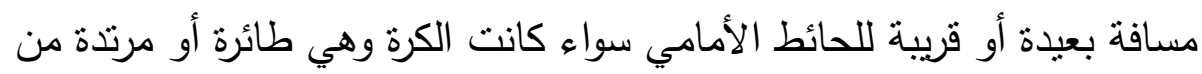

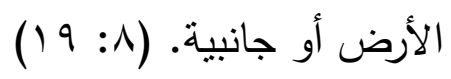

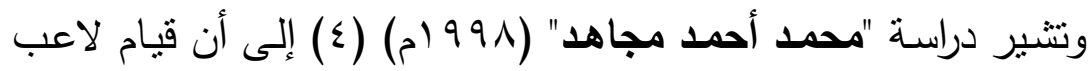

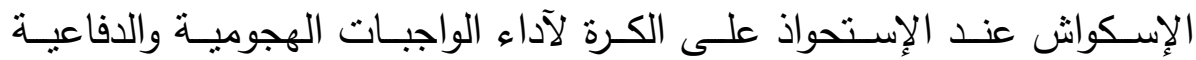

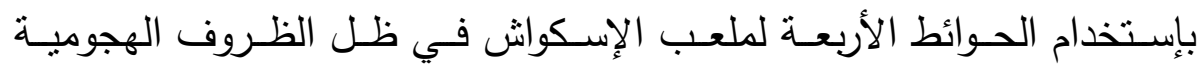
والدفاعية أظهر أهمية إتقان المهارات الأساسية وتطويرها والتي قد تكون أحد الجوانب التي تحدد نتيجة المباراة. هدف البحث :

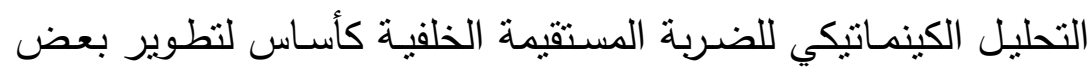
التمارين لإستخدامها خلال مرحلة التثبيت في التعلم الحركي من خلاله :

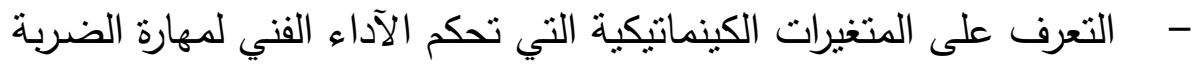
الخلفية المستقيمة. - - التعرف على المواصفات الفنية لبعض التمرينات لإستخدامها خلال مرحلة النتييت فى التعلم الحركي. تساؤلات البحث : 


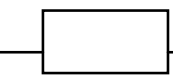

- ما - مالمتغيرات الكينماتيكية التي تحكم الآداء الفني لمهارة الضربة الخلفية

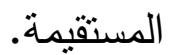
- ما مواصفات الفنية لبعض التمرينات لإستخدامها خلال مرحلة التثبيت في

$$
\text { مصطلحات البحث : التعلم الحركي. }
$$

- الضربة الخلفية: Back Hand

هي إحدى المهارات الأساسية والمهمة في لعبة الإسكواش والتي تسمح

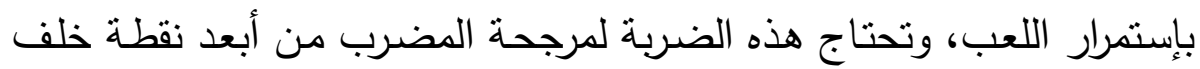

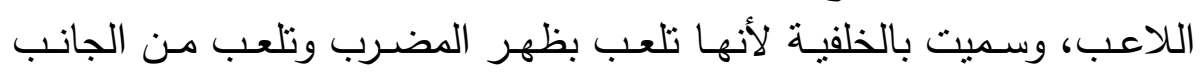
الأيسر من الأيمن.

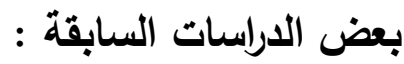

أولا: الدراسات العربية :

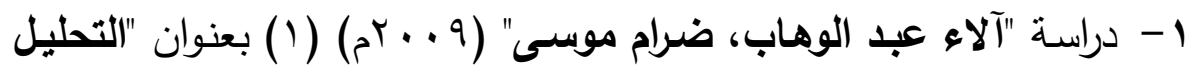

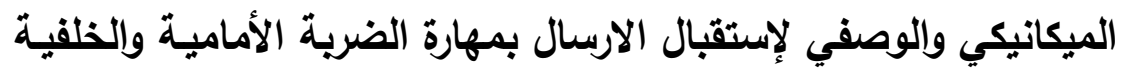

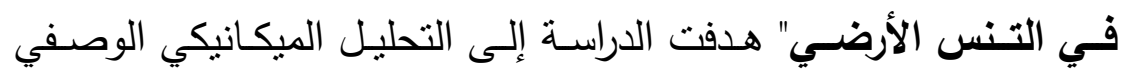

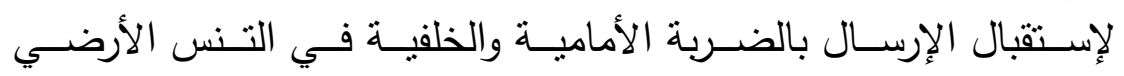

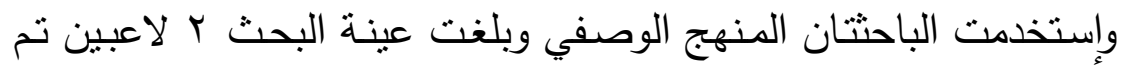

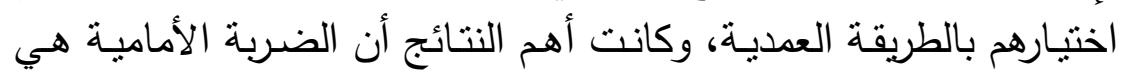

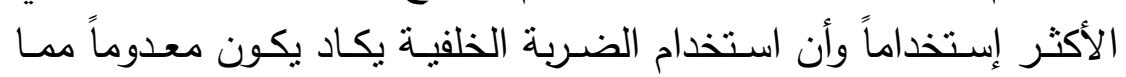
يؤدي لفقدان النقاط لدى اللاعبين.

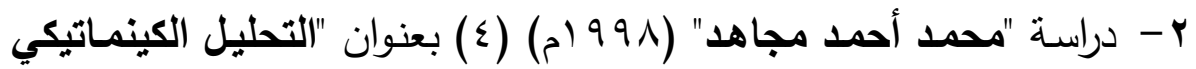

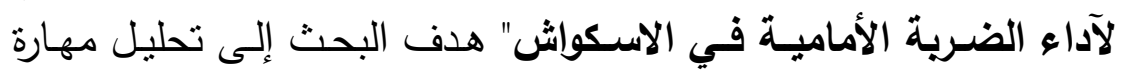

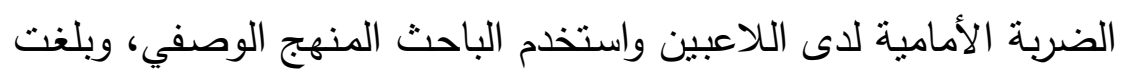

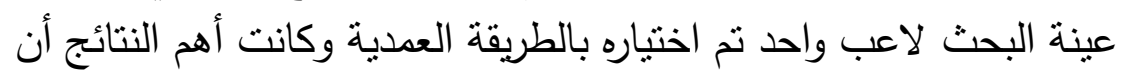

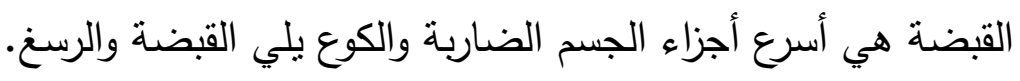




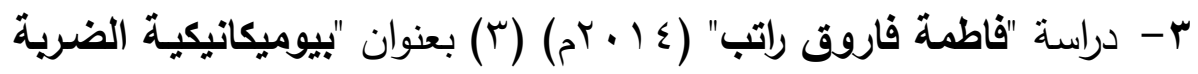

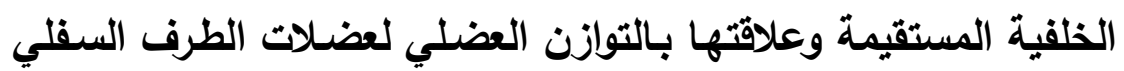

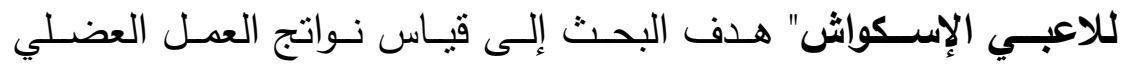

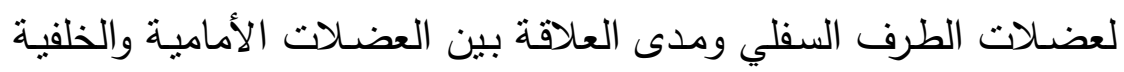

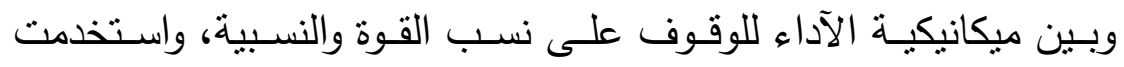

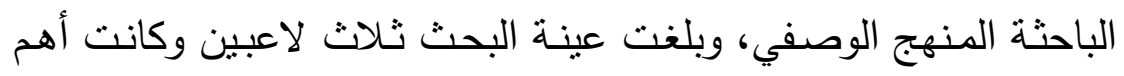

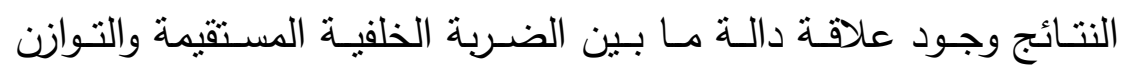
لعضلات الطرف السفلي.

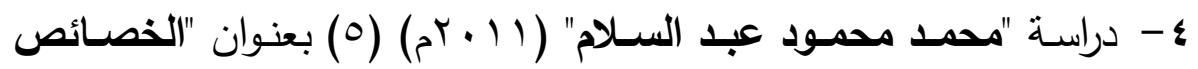

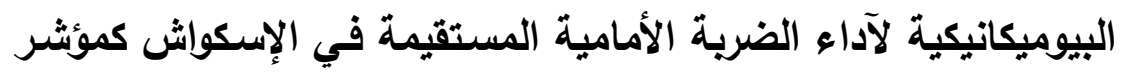

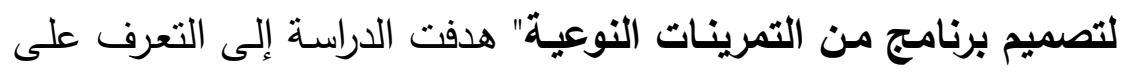

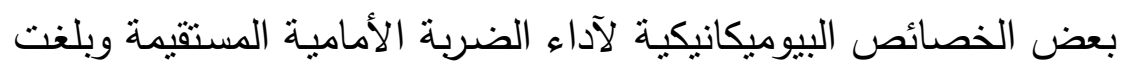

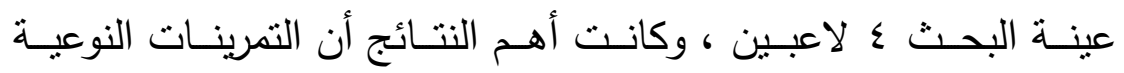

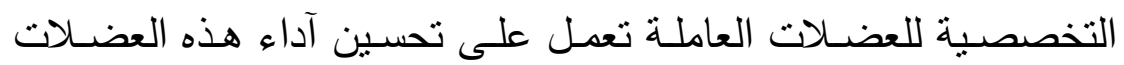

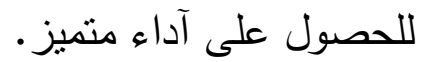

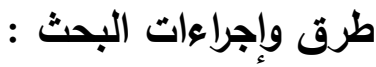
منهج البحث : ماءع إستخدم الباحث المنهج التجريبي للقيام بالتحليل الحركي لمهارة الضربة

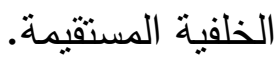

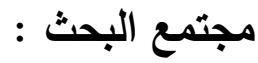

يمثل مجتمع البحث لاعبي الإسكواش بمحافظة أسيوط للموسم الرياضي

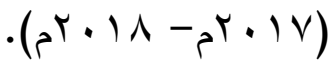

$$
\begin{aligned}
& \text { عينة البحث : }
\end{aligned}
$$

تم اختيار عينة البحث بالطريقة العمدية من لاعبي الإسكواش بمحافظة إندا

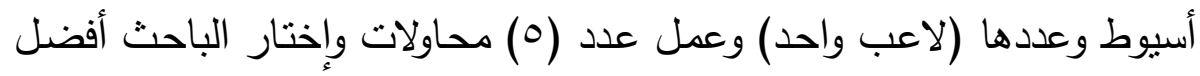

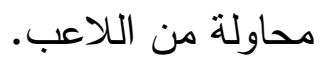

مجلة أسيوط لعوم وفنون التربية الرياضية 
أولاً : الأجهزة والأدوات المساعدة البات لجمع البيانات :

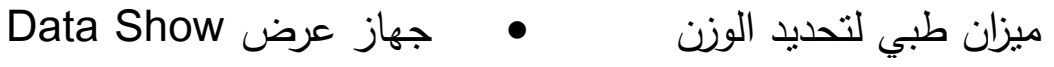

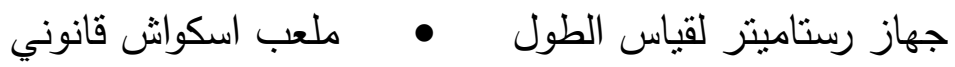

ثانياً: أدوات التحليل الحركي :

وحدة سمي للتحليل الحركي Simi Analysis عدد ( () برنامج لامتداد

$$
\text { السمى } 2 \text { - للتحليل ثناثى الابعاد. }
$$

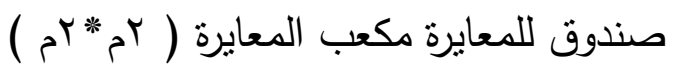

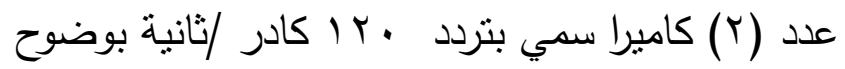

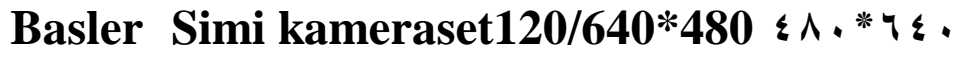

عدد (Y) دوائر ضوئية سمي تثبت على مقدمة عدسة الكاميرا

$$
\text { عدد (1) حامل ثثلاثى نظام سمي }
$$

عدد (Y) كابل لعرض بيانات

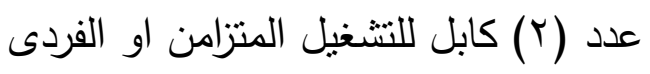

خطوات إجراء البحث :

- تحليل المراجع العلمية المتخصصة في مجال رياضـة الاسكواش والتحليل

$$
\text { الحركي. }
$$

- تصميم استمارة استطلاع للخبراء رأي لتقييم

$$
\text { - - مرض الاستمارة على الخبراء. }
$$

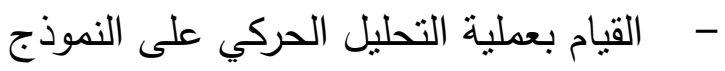

$$
\text { - - إجراء المعاملات الإحصائية. }
$$

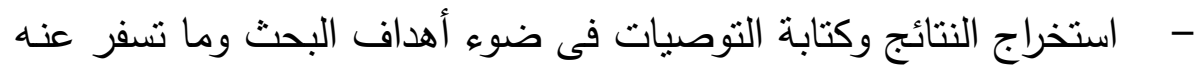

$$
\text { الدراسة. }
$$

المعالجات الاحصائية : الأن

إستخدم الباحث المعالجات الاحصائية التالية :

$$
\text { المتوسط الحسابي. }
$$




$$
\text { • }
$$

\begin{tabular}{|c|c|c|c|}
\hline نسبته المئوية & الزمن & المقطع & المرحلة \\
\hline 84.0 & 1.78 & 178 & التمهيدية \\
\hline 13.2 & 0.28 & 28 & الرئيسية \\
\hline 2.8 & 0.06 & 6 & النهائية \\
\hline 100.0 & 2.12 & 212 & المجموع للمهارة ككل \\
\hline
\end{tabular}

التركيب الزمنى ونسبته المئوية خلال آداء المراحل (التمهيدية

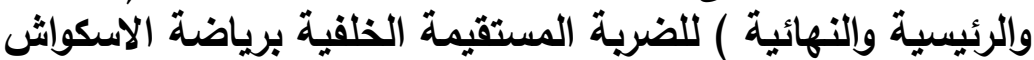

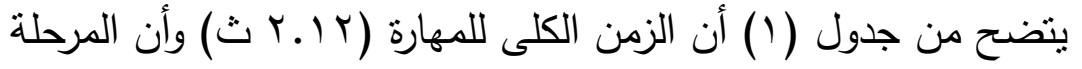

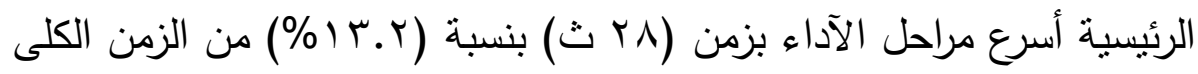

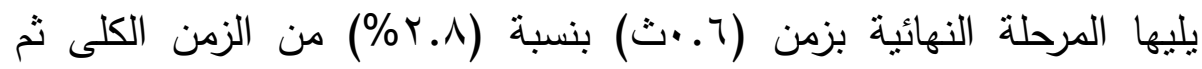

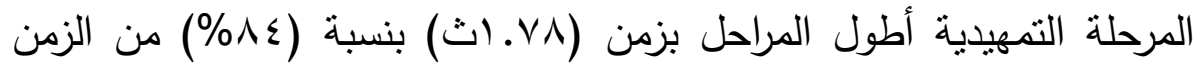

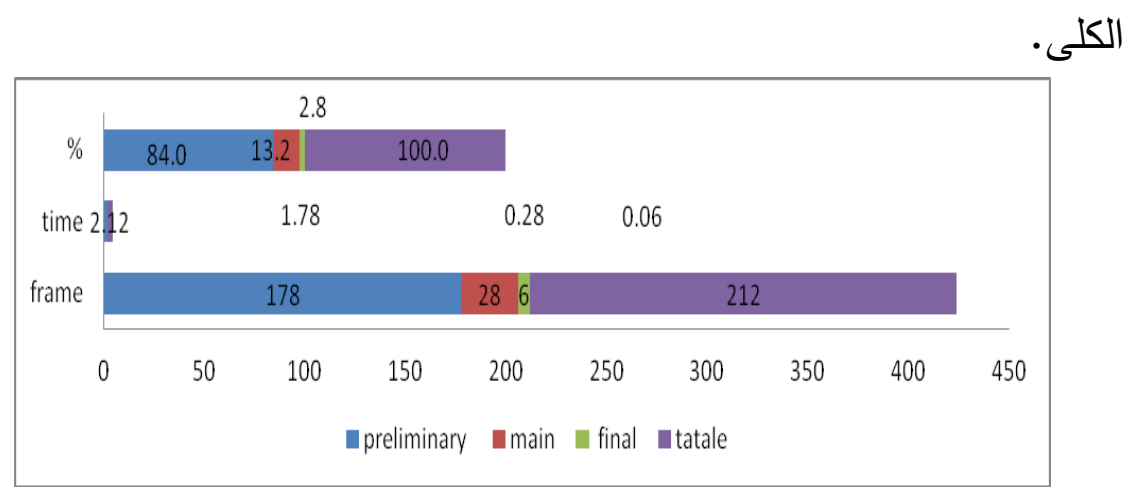

\section{شكل (1)}

التسارع اللحظى لأجزاء الجسم المشاركة فى آداء الضربة المستقيمة الخلفية برياضة الإسكواش خلال المرحلة (التمهيدية) 

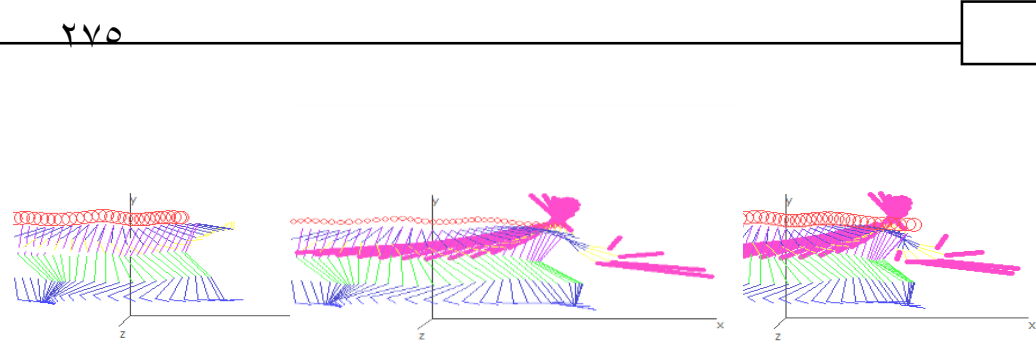

\section{شكل (r) (ب)}

التسارع اللحظى لأجزاء الجسم المشاركة فى آداء الضرية المستقيمة

الخلفية برياضة الإسكواش خلال المرحلة (التمهيدية)

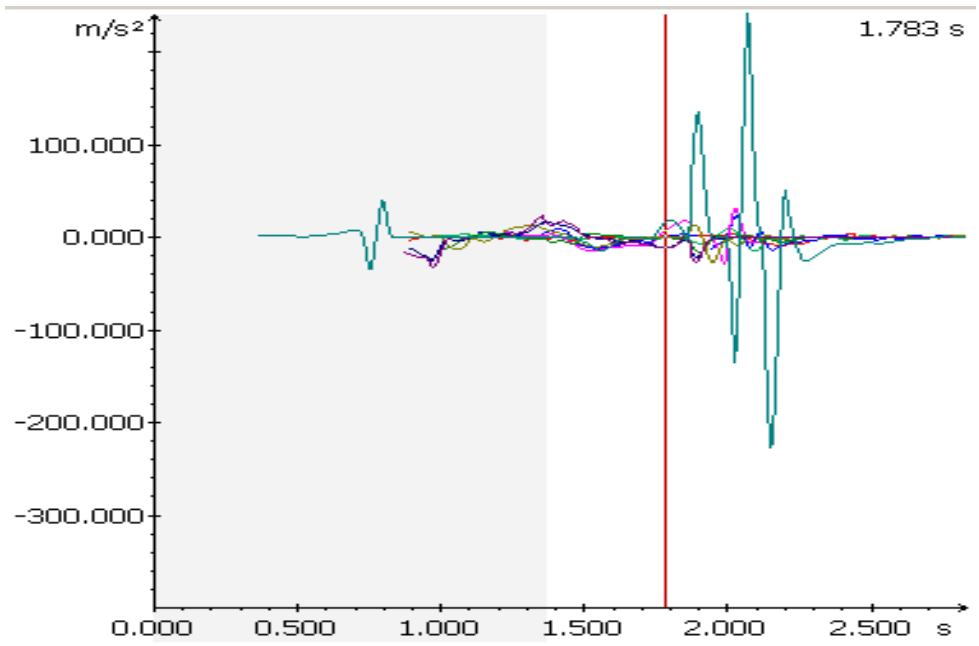

1.529 head 2D a(abs)

0.368 right shoulder 2D a(abs)

0.558 right elbow 2D a(abs)

7.841 right wrist $2 \mathrm{D}$ a(abs)

0.362 right hip 2D a(abs)

-0.113 right knee 2D a(abs)

-10.964 right ankle-bone 2D a(abs)

-11.041 right foot 2D a(abs)

16.070 ref-1 2D a(abs)

$$
\text { شكل (r) آمثاركة }
$$

التسارع اللحظى لأجزاء الجسم المشاركة فى آداء الضرية المستقيمة الخلقية

$$
\text { برياضة الإسكواش خلال المرحلة (التمهيدية) }
$$

يتضح من شكل (r) تفاوت محصلة التسارع لمفاصل الجسم

المشتركة فى آداء المهارة وجاءت أعلى تسارع للأجزاء بالترتيب التتازلى

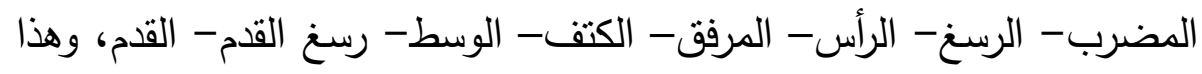

مجلة أسيوط لعلوم وفنون التربية الرياضية 


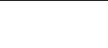

يعضدد وجود تمهيد لنتبيت أجزاء الجسم من أسفل إلى أعلى ولإرتكاز تمهيداً

لضرب الكرة.

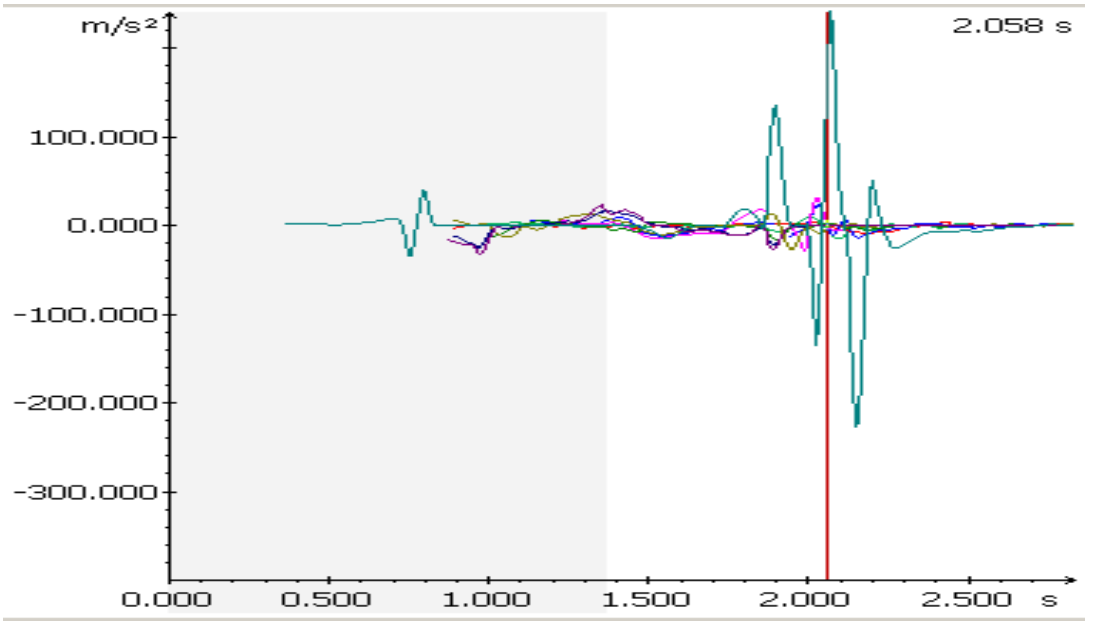

1.256 head 2D a(abs)

-3.420 right shoulder $2 \mathrm{D}$ a(abs)

2.320 right elbow $2 \mathrm{D}$ a(abs)

2.445 right wrist $2 \mathrm{D}$ a(abs)

2.412 right hip 2D a(abs)

-4.225 right knee 2D a(abs)

-0.331 right ankle-bone 2D a(abs)

0.051 right foot $2 \mathrm{D}$ a(abs)

166.288 ref-1 2D a(abs)

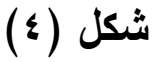

التسارع اللحظى لأجزاء الجسم المشاركة فى آداء الضربة المستقيمة الخلقية برياضة الاسكواش خلال المرحلة (الرئيسية)

يتضح من شكل (ع) تفاوت محصلة التسارع لمفاصل الجسم المشنركة

فى آداء المهارة وجاءت أعلى تسارع للأجزاء بالتزتيب التنازلى المضرب

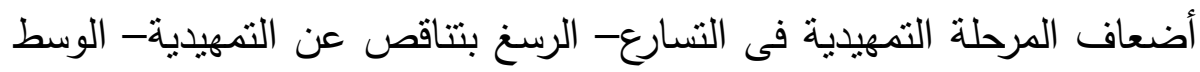
بتزايد عن التمهيدى- المرفق بتزايد عن التمهيدي- الرأس تتاقص طفيف عن التمهيدي- القدم بتزايد عن التمهيدي- رسن القدم بتزايد عن التمهيدى- الكتق بتتاقص عن التمهيدي- الركبة بتتاقص عن التمهيدي، ويلاحظ أن التتاقص يتم 


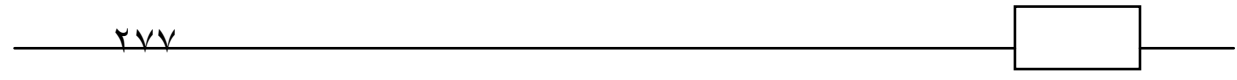

لأجزاء الرسغ- الرأس- الكتف- الركبة، فيعد هذا إمتصاص وتثبيت لحظة

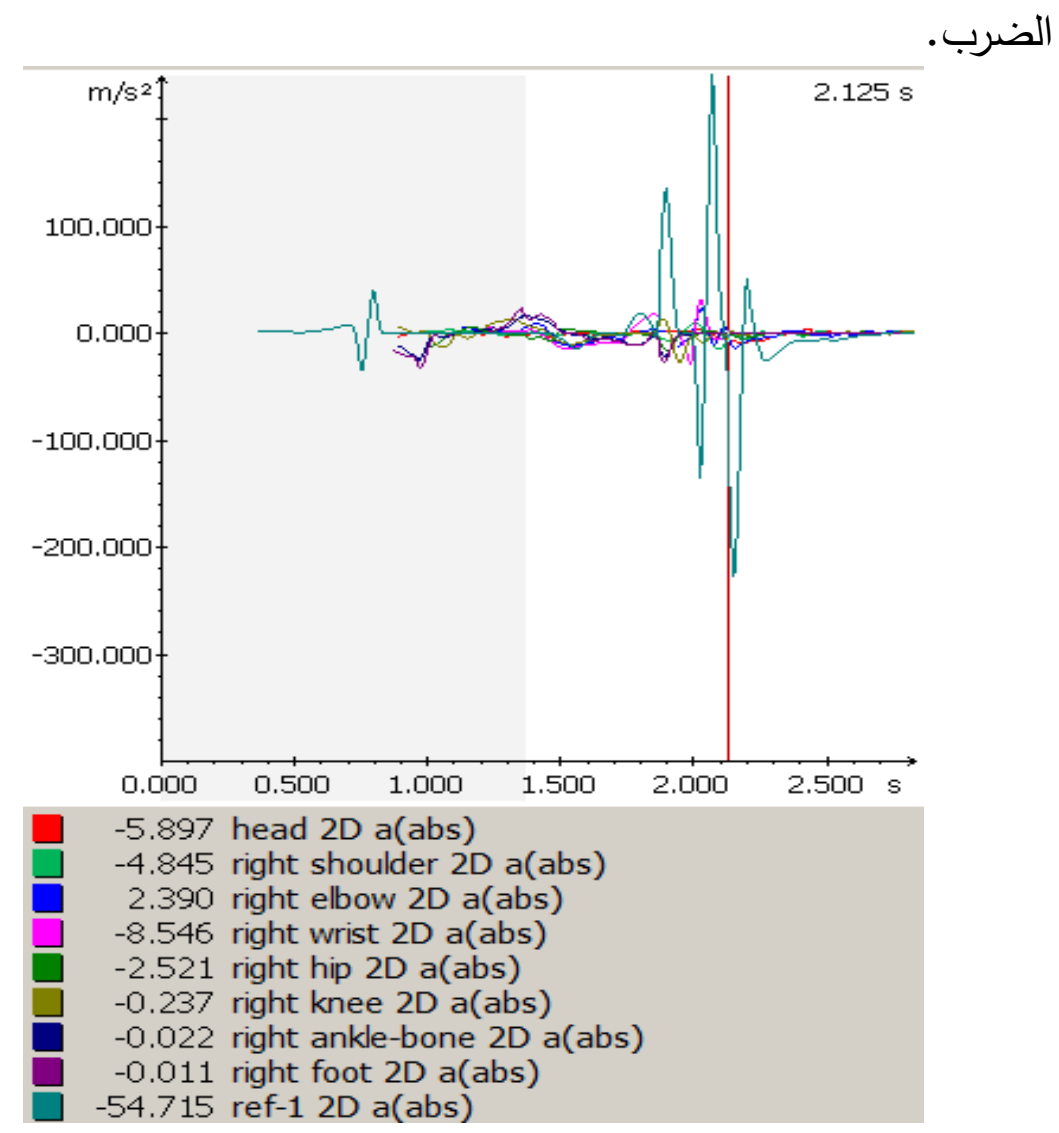

شكل (0)

التسارع اللطظى لأجزاء الجسم المشاركة فى آداء الضرية المستقيمة الخلفية برياضة الإسكواش خلال المرحلة (النهائية)

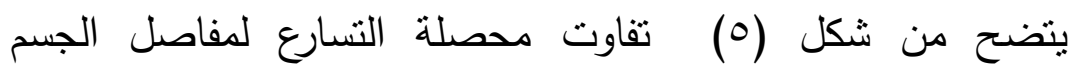

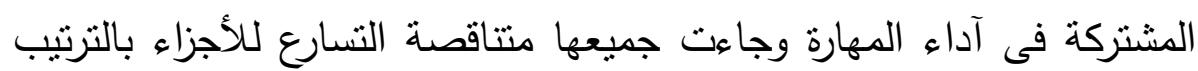
التتازلى المضرب- الرسغ- الرأس- الكتق- الوسط- الركبة- رسغ القدم- القدم بينما المرفق ينسارع إيجابياً منقارب مع المرحلة الرئيسية. مجلة أسيوط لعلوم وفنون التربية الرياضية 
خصائص مراحل الآداء والتمرينات المقترحة لكل منها التمرين خصائصها المرحلة

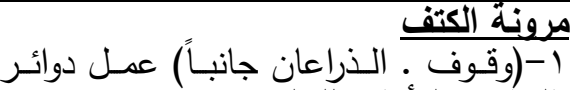

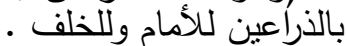

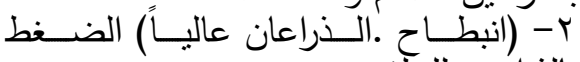
بالذراعين للخَّف

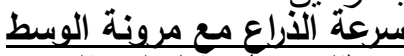

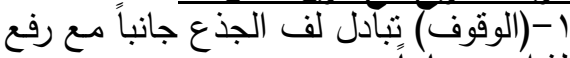

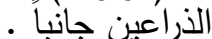

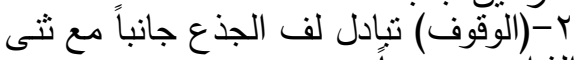

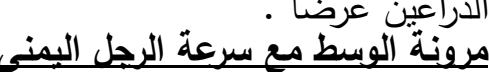

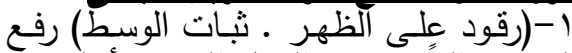

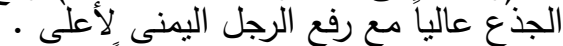

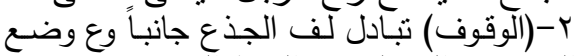
الكفين في الوسط ورفع الركبة البمني الئيا

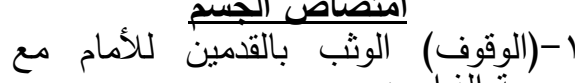

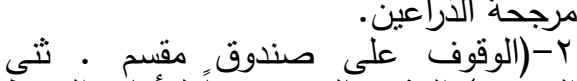
الركبنين) الوثب بالكدمين معاً للأكام والهيوط المتصاص لآداء مرونة الكتف

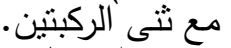

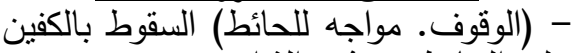
على الحائط مع ثنى الذراعين. سرعة الذراع

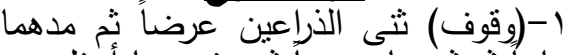

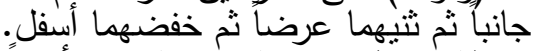

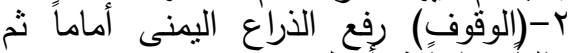
عاليا فجانباً ثم أسفل.

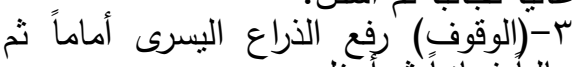

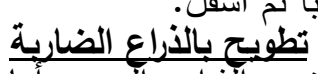
عاليا فجانباً ثم أسفل.

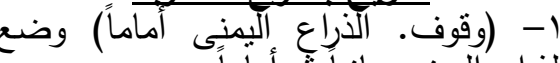
الذراع اليمنى جانباُ تُّم أمأماً.

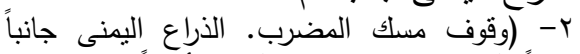
مائلاً لأسفل) تطويح الذراع لأعلى وأماماً.

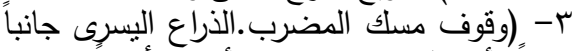
مائلاً لأسفل) تطويح الذراع لأعلى وأماماً

تفاوت محصلة التسارع لمفاصل الجسم المشتنركة في آداء المهارة لماهي وجاءت أعلى تنتئ فئرع للأجزاء

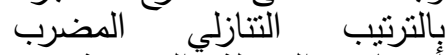
أضضعاف المرحلة "التمهيدية في التئية

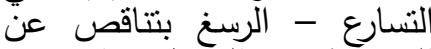

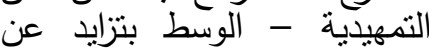
التمهيدي - المرفقيد بتزايد عن الونيد التمهيدي - الرأس تتاقص طفيديف بتربد طنيد عن التمهيدي - القدم بتزايد عن عن التيدي التمهيدي - رسن القدم بتزايد عن عن عن التيدي

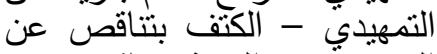

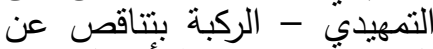
التمهيدي ، وبيلاحظ أن التخاقص

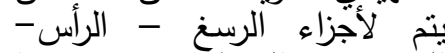

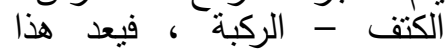
إمتصاص وتثبيت لحظة الضرب 


\section{جدول (ז)}

خصائص مراحل الآداء والتمرينات المقترحة لكل منها

\begin{tabular}{|c|c|c|}
\hline التمرين & خصائصها & المرحلة \\
\hline 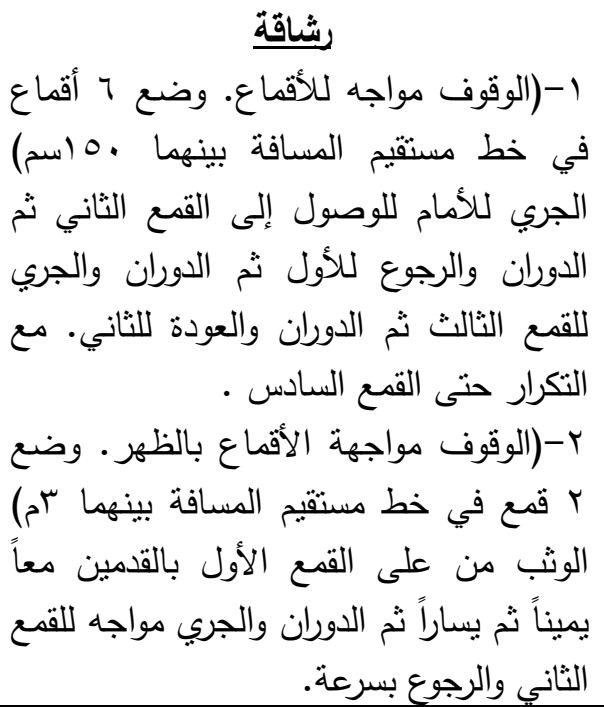 & 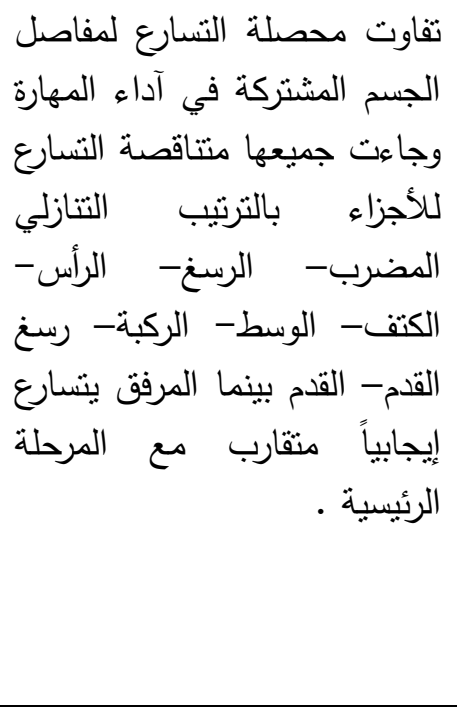 & 事 \\
\hline
\end{tabular}

التوصيات : (1) - n

1- إستخدام التمرينات التى خلصت إليها الدراسة أثتاء التعليم بمرحلة التثيـت

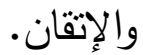

r- إستخدام وسـئل قياس دقيقة التى إستخدمت فى الدراسـة الحالية للتوصل إلى تمرينات مقترحة بمراحل التعليم المختلفة. بـ- العمل على تقنـين التمرينـات المقترحـة المسـتخدمة خـلال مراحل التعلم الثناثة على غرار ما تم بالدراسة الحالية. ع- إجراء المزبد من الدراسات حول التمرينات فى فترة الإعداد البدنى بمراحل التعلم المختلفة. 


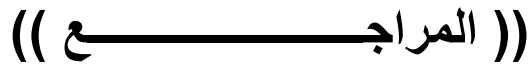

أولا: المراجع العربية :

1 - آلاء عبد الوهـاب، ضـرام موسـى: التحليل الميكانيكي والوصفي لإستقبال

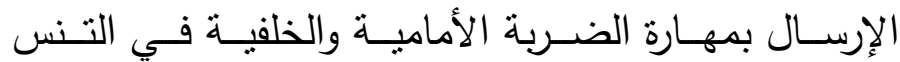
الأرضي، بحث علمي منشور ، مجلة القادية لعلوم التربية الرياضية، المجلد التاسع، العدد الثالث، 9 ، . . بم. ץ - طلحة حسين حسام الدين: "الأسس الحركية والوظيفية للتدريب الرياضي"،

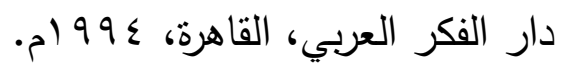

ب- فاطمـة فـاروق راتـب: بيوميكانيكيـة الضـربة الخلفيـة المستقيمة وعلاقتهـا

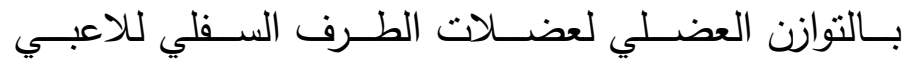
الاسـكواش، رسـالة دكتـوراه، غيـر منشــورة، كليـة التربيـة الرياضية، جامعة المنيا، ع 1 ـ برم.

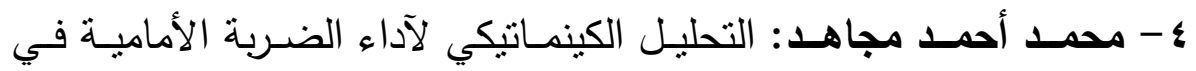
الاسـكواش، رسـالة ماجسـتير، غيـر منشـورة، كليـة التربيـة الرياضية، جامعة طنطا، 991 (م. ه- محمــد محمـود عبــ السـلام: الخصـائص البيوميكانيكيـة لآداء الضـربة

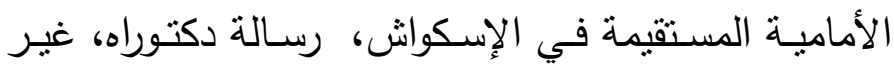

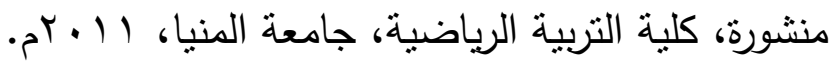
צ- محمود عبد الحليم عبد الكريم: منظومة الرياضة المدرسية (التعليم الجيد - مهارات التدريس - المعلم ومعـايير الكفاءة)، دار الفكر

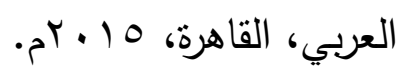

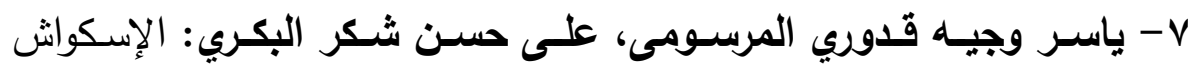
الثامل، كلية التربية البدنية وعلوم الرياضـة، جامعة بغداد،

$$
\text { العراق، } 10 \text { م برم. }
$$


:ثاتيا: المراجع الأجنبية :

8- Dinid Dollins : Get ready for Squash a complete training Programs, a bsrrat international. London, 1999.

9- Tim Bacon : Tennis Teaching Coaching and divesting Programs prentice- Hall. Wc., New Jersey, 1997.

10- Tiley, D, Gillam : Science of fitness of Squash Philip Institute of Technology, Melbourne, 1998 